\title{
Estrategias y Proyectos profesionales de las estudiantes de carreras "masculinas"
}

\author{
Alicia Itatí Palermo
}

\section{Resumen}

En este artículo consideramos los aspectos relacionados con la elección, por parte de las mujeres, de carreras universitarias no tradicionales para su sexo y las dificultades que ellas encuentran en su paso por la universidad y en las expectativas sobre su futuro desarrollo profesional.

Consideramos que el ingreso a una carrera universitaria constituye una instancia crucial del proceso de profesionalidad, proceso que se va construyendo a lo largo de la vida de una persona, a través de distintas instancias.

A partir de los resultados de un trabajo de investigación realizado en la Universidad Nacional de Luján, exploramos las significaciones que ellas tienen durante el trayecto de su carrera universitaria en relación con su elección y nos detenemos en un concepto que hemos creado a partir del análisis de los datos: estrategias anticipatorias de su futura inserción laboral.

\section{Palabras clave}

Educación universitaria, educación y género, carreras no tradicionales, profesionalidad, mujeres.

\section{Abstract}

This article considers the aspects related with the election, by women, of nontraditional careers for their sex and the 
difficulties they find on their way through university and on their expectations about their future professional development.

We believe that admission to a university career is a crucial instance of the professionalism process, a process that is built along a person's life, through various levels.

Based on the results of a research of the National University of Luján, we explore the meanings that they have during the course of their university career in relation with their choice and we stop on a concept that we have created from the analysis of data: anticipatory strategies for their future employment.

\section{Keywords}

University education - education and gender - nontraditional careers - professionalism women. 
" $Y$ entonces, cuando me reciba de Ingeniera Agrónoma tengo un montón de incertidumbre de a lo que me voy a dedicar; eso sí, creo que es una incertidumbre que no tengo saldada, o sea tengo decidido de lo que no quiero trabajar, pero no sé de lo que quiero trabajar".

(Lara, 23, $3^{\text {er }}$ año)

\section{Introducción}

En el año 1901 se gradúa la primera camada de egresados de la Facultad de Filosofía y Letras de la Universidad de Buenos Aires. Se trataba de cuatro mujeres y de cinco varones.

Una de esas jóvenes, Elvira López, se gradúa con la tesis: "El movimiento feminista". En ella describe cómo en distintos países las mujeres estaban accediendo a los estudios universitarios, destacando el tipo de carrera en la que ingresaban y las reacciones que despertaban en la sociedad de la época.

En ese año, en Argentina se contaba con muy pocas mujeres en la universidad en carreras superiores. El camino se había iniciado con medicina, como ocurrió en casi todos los países occidentales, aunque con la apertura de la facultad de Filosofía y Letras se reorientaron las elecciones femeninas hacia las carreras de esa facultad (véase Palermo, 2006).

A más de un siglo de que las mujeres ingresaron en la universidad, son mayoría en las aulas universitarias. Esta feminización de la educación universitaria se vio acompañada de una diversificación de las opciones, aunque algunas carreras como las ingenierías siguen siendo un bastión masculino en nuestro país y en casi todos los países occidentales, con una tendencia lenta pero creciente al aumento de la participación femenina.

Después de más de un siglo desde que accedieron a la universidad, las mujeres en ese ámbito constituyen un objeto de estudio. La preocupación que antes estaba puesta en otros niveles educacionales ha llegado al nivel superior.

Robles San Juan y Anguita Martínez (1993) afirman que las preguntas actuales frente a la educación universitaria femenina son: ¿qué mujeres son las que acceden a las universidades?, ¿a qué tipo de estudios ingresan? y ¿significa la incorporación de las mujeres a los estudios superiores su acceso a la ciencia y a la cultura? 
En efecto, si bien las mujeres somos mayoría en las aulas universitarias y hemos diversificado nuestras opciones, las elecciones diferenciadas por sexo aún persisten. Las carreras científicas y las tecnológicas son un bastión masculino en casi todos los países.

Esta diferenciación de elecciones se apoya en las divisiones socio-sexuadas del saber, en la distinción entre "saberes masculinos" y "saberes femeninos", en la "manera en que en cada sociedad se instituyen las relaciones entre los sexos y cómo estas relaciones influyen en su vínculo con el saber". Aun cuando las mujeres hayan accedido a distintos saberes y disciplinas, en la actualidad las ciencias exactas y naturales y las carreras técnicas, principalmente la Ingeniería constituyen "territorios masculinos" (Mosconi, 1998).

Podríamos agregar, a más de un siglo de que las mujeres accedieran a la universidad y que son mayoría en las aulas universitarias, las siguientes preguntas: ¿qué factores intervienen en las elecciones que ellas hacen de una carrera universitaria?, ¿por qué sigue habiendo carreras en las que son absoluta minoría?, ¿qué significado tiene para ellas la elección de una carrera "masculina"? y ¿cuáles son sus proyectos profesionales?

Algunos investigadores han tratado de explicar tanto la orientación diferencial de las jóvenes hacia determinadas carreras, como su escogencia atípica por la ingeniería, considerando además sus trayectorias y logros escolares, así como sus trayectorias e identidades profesionales.

La escogencia de una carrera "significada para el otro sexo" se presenta como un campo rico para el análisis y búsqueda de explicaciones teóricas en el contexto de las teorías de la construcción de la identidad de género y de la reproducción.

Para Arango (2006: 37), "las investigaciones que se interesan por situaciones atípicas, por los éxitos improbables, como los de las niñas en orientaciones masculinas, se inscriben en una ampliación crítica de las teorías de la reproducción, en la medida en que no se subestiman los mecanismos de imposición y de dominación masculina y la reproducción de las herencias sociales, pero le prestan mayor atención al juego de actores, a su movilización en torno al éxito escolar o social y a la apropiación de sus herencias". Estos trabajos nos brindan un panorama bastante complejo y variado de los factores que intervienen en las escogencias femeninas por carreras significadas para varones.

En esta línea, Duru Bellat y Jarlegan (2001) rechazan la idea de que las niñas sean las víctimas del sistema escolar en forma unívoca. Las autoras sostienen las hipótesis de que la imagen que se tiene del futuro define las escogencias.

Duru Bellat (1990) afirma que las niñas tienen buenas razones para escoger alternativas que se adapten mejor al lugar que se les ha asignado en la familia y en la sociedad, y que estas elecciones son producto de estrategias conscientes y razonadas.

Además de las escogencias, otros aspectos que se relacionan con la participación femenina en la ingeniería son: la desigualdad de distribución de varones y mujeres en 
las diferentes ramas de la ingeniería y las distintas trayectorias que desarrollan en el ejercicio profesional, así como la articulación de los mecanismos de construcción de la profesionalidad con el género.

Desde este último aspecto es importante considerar la construcción de los imaginarios profesionales. Entendemos que el proceso de profesionalidad se desarrolla a lo largo de toda la vida de una persona, y que la elección de una carrera es un momento de dicho proceso.

En este artículo, nuestro objetivo es explorar las estrategias y los proyectos profesionales que elaboran, durante el transcurso de sus estudios universitarios, las jóvenes que eligieron dos carreras que tienen absoluta mayoría de varones: Ingeniería Industrial e Ingeniería Agronómica, así como las significaciones que les otorgan a estas estrategias y proyectos. Dichas significaciones nos proveen el punto de vista de las propias jóvenes y la comprensión del sentido de sus acciones.

\section{Las mujeres en carreras científicas y tecnológicas: breve estado del arte}

Existe una importante preocupación por estimular el acceso de las mujeres a las carreras técnicas y científicas. No solo se han estado desarrollando medidas de acción positiva y de promoción de la igualdad de oportunidades, sino que también se han llevado a cabo diferentes investigaciones, principalmente desde los centros o áreas de las mujeres o de género de las diferentes universidades de los países occidentales. Sin embargo, algunos autores, como Brush (1991), consideran que las jóvenes que no optan por carreras científicas y tecnológicas podrían tener un comportamiento mucho más inteligente que aquellos que quieren promover por parte de ellas elecciones no tradicionales sin considerar los reales obstáculos que tienen durante sus estudios y su trabajo profesional.

Estos obstáculos, que para el autor son eficaces en excluir a las mujeres de las carreras científicas y tecnológicas, son de diverso tipo. Brush destaca los siguientes: a) el estereotipo que asocia la ciencia y la tecnología con varón, b) la actitud sexista de los estudiantes varones, de los profesores de la universidad y de los compañeros y jefes en el trabajo profesional, c) las dificultades para progresar en la carrera profesional y d) la concepción de la ciencia y de la tecnología como "actividades masculinas".

Algunas teorías intentan explicar la poca representación de mujeres en carreras científicas y técnicas. La teoría del capital humano postula que "los distintos tipos de discriminación que reducen la probabilidad de transformar las cualificaciones laborales adquiridas por medio de la educación en ganancias adicionales desplazan hacia abajo la curva de demanda de educación".

Desde este punto de vista, podría pensarse que las elecciones de las mujeres se orientarán hacia carreras que les permitan esas "ganancias adicionales". Es decir que las 
facilidades o dificultades que existan para ellas en el ejercicio de una determinada profesión pueden producir el efecto de alentarlas, o por el contrario, desalentarlas en la elección (Rodríguez, 2000). Rozenblatt (1999) afirma que "la calificación y la competencia son instrumentos de clasificación que integran a su vez otras clasificaciones, entre ellas la jerarquía de funciones en términos de género: funciones femeninas y masculinas". El autor postula la existencia de una construcción social de la diferencia en las competencias profesionales, lo que hace que los jóvenes de distinto sexo se orienten hacia elecciones profesionales y empleos diferenciales.

Otro tipo de explicación es el de la "teoría fabricando género, que sostiene la hipótesis de que la elección de las disciplinas y de las carreras en el sistema escolar es una cuestión de identidad personal, de confianza en sí mismo también y no tiene mucho que ver con las competencias sino con el estar en equilibrio con lo que se hace. Esta teoría también construye la hipótesis de que existe una lucha permanente entre los sexos con respecto a su posición en el aspecto social. Esta lucha empieza en el espacio escolar en la medida en que el espacio escolar prefigura el espacio social. La elección de las orientaciones en la escuela va a ser un elemento determinante del posicionamiento escolar y profesional. En esta lucha, la situación actual es que las mujeres tratan de ganar territorios masculinos, como en carreras científicas y técnicas... Inversamente, los varones no se interesan por el territorio femenino, los territorios femeninos como tales son desvalorizados" (Mosconi, 1998).

Esta identidad personal y confianza en sí mismo se manifestarán, por ejemplo, en elegir carreras "masculinas" cuando existe determinada familiaridad o cuando las mujeres tuvieron éxito en determinadas materias en el secundario.

Candace West y Don Zimmerman (1999) afirman que el sexo es construido por las personas individuales a través de medios psicológicos, culturales y sociales. "Hacer género implica un complejo de actividades perceptivas, interactivas y micropolíticas socialmente guiadas que conforman actividades particulares como expresiones de la naturaleza femenina y de la masculina... en un sentido, por supuesto, son los individuos los que hacen género. Pero es un hacer situado, realizado en presencia virtual o real de otras personas, que se supone que están orientadas hacia su producción. Más que una propiedad individual, consideramos el género como un elemento emergente de situaciones sociales: es tanto el resultado como la razón fundamental de varios arreglos sociales y un medio de legitimar una de las divisiones fundantes de la sociedad" (West y Zimmerman, 1999: 111). Es decir que los individuos "hacen género" en las situaciones de interacción social; el género es por lo tanto producto de prácticas sociales, en las que varones y mujeres tienen que "rendir cuentas" acerca de su comportamiento femenino o masculino, por lo que dependerá de las diferentes situaciones que vivan, los recursos que implementarán para "hacer género". Los autores afirman que cuando 
una persona adopta comportamientos asociados con la otra categoría sexual ${ }^{1}$, se produce un dilema que necesita ser resuelto a través de diversos mecanismos. Por ejemplo, cuando se elige una carrera "significada para el otro sexo", es necesario llegar a "arreglos sociales" que impliquen asumir públicamente un comportamiento adecuado para su sexo. A un desafío le sigue, por decirlo de alguna manera, un autodisciplinamiento.

Christine Williams (1989) resalta la importancia de estudiar cómo el género es activamente construido en las profesiones no tradicionales para un determinado sexo. Ella afirma que, si bien el género es siempre socialmente construido por los individuos, en las profesiones no tradicionales este proceso se hace más evidente, por lo cual el estudio del comportamiento de hombres y mujeres en esos espacios puede ayudarnos a comprender el proceso de construcción del género en otras situaciones, toda vez que en las profesiones no tradicionales, ellas y ellos tienen que "trabajar" para construir lo que se considera el género apropiado. Este proceso los lleva a reforzar su identidad femenina o masculina.

En relación con las investigaciones, estas prestan especial atención al ambiente de enseñanza en las instituciones educativas mixtas, encontrando que el mensaje que reciben las estudiantes es que sus compañeros son más importantes y que el trabajo realizado por ellas es de menor calidad e interesa menos a los profesores. En las instancias de interacción, las jóvenes son silenciadas e invisibilizadas, se presta más atención a lo que dicen o hacen sus compañeros.

Esto repercute en el nivel de autoconfianza, y muchas jóvenes que "empezaron queriendo ser ingenieras, arquitectas o médicas, se conforman con la enseñanza, y muchas veces optan por abandonar la idea de hacer una carrera profesional" (Gascón Vera, 1995).

En España, Elejabeitía y López Sáez (2003) realizaron desde el Instituto de la Mujer una importante investigación sobre estudiantes mujeres de carreras técnicas, tanto secundarias como universitarias y sobre ingenieras con distinta antigüedad en el ejercicio profesional.

Las autoras plantean que en la elección de la carrera juegan no solo las aficiones personales, sino también las expectativas de empleo, por lo cual las dificultades que las jóvenes visualizan en el ejercicio de las profesiones técnicas pueden disuadirlas de elegir ingeniería u otra carrera tradicionalmente considerada masculina.

Las jóvenes que eligen carreras técnicas son buenas estudiantes, les gustan las ciencias y saben que la carrera elegida proporciona estatus y mayores oportunidades laborales.

\footnotetext{
${ }^{1}$ West y Zimmerman (1999) diferencian entre sexo, categoría sexual y género. El sexo está definido por la biología, la categoría sexual es una clasificación social como niño o niña, hombre mujer. El género es una construcción que realizan los individuos al comprometerse con una determinada conducta, con riesgo de rendición de cuentas.
} 
Sin embargo, a lo largo de su trayectoria educativa y en el ejercicio profesional se encuentran con innumerables dificultades, que no se les presentan a sus compañeros. Algunas de estas dificultades son:

1) falta de modelos de identificación;

2) sentimiento de ser consideradas por la sociedad menos femeninas;

3) necesidad de controlar el futuro profesional, lo que hace que se culpen a sí mismas por las dificultades que anticipan que tendrán en su carrera profesional;

4) percepción de que la valoración de familiares, profesores y estudiantes varones respecto de su elección de carrera es baja.

Las autoras contrastan estas dificultades que perciben las estudiantes con las opiniones de las ingenieras entrevistadas, que se encuentran en distintos momentos de su carrera profesional.

Ellas afirman estar satisfechas con su trabajo profesional, por estar realizando trabajos en los que se encuentran a gusto y que las obligan a mantenerse actualizadas profesionalmente. Manifiestan tener dificultades con el horario, ya que tienen poco tiempo libre; tienen bajas expectativas de ascenso profesional y consideran que su salario es más bajo que el de los varones. Sin embargo, expresan que estas dificultades no menoscaban su satisfacción respecto del trabajo, porque aquella pasa por sentirse bien con lo que hacen, y no aspiran a obtener puestos de mayor responsabilidad y salarios más altos. Tampoco perciben discriminaciones por parte de sus compañeros de trabajo y jefes.

Esos resultados coinciden con los de Smichtt y colaboradores, quienes realizaron una investigación sobre mujeres ingenieras en Inglaterra (citado por Elejabeitia y López Sáez, 2003) concluyendo que los grupos en desventaja y discriminados tienden a minimizar la importancia de la discriminación, como un mecanismo que les permite mantener la ilusión de control sobre su situación, para así conservar un estado de bienestar psicológico y proteger su autoestima.

En Francia, Daune Richard (1995) realizó una investigación sobre el ingreso de las mujeres en carreras masculinas de nivel técnico superior. La autora señala que "las mujeres se alejan más de los empleos técnicos cuanto más cercanos a la fabricación estén, y cuanto más pertenezcan a sectores socialmente valorizados, es decir considerados como determinantes para la reproducción social (armamento y por hipótesis, nuevas tecnologías). Por fin y de manera más general, cualquiera sea la naturaleza de los empleos, tienen tanto menor acceso en la medida en que comporten funciones de supervisión y responsabilidades jerárquicas".

Francia es uno de los países europeos con mayor progreso de la feminización de las formaciones en ingeniería; sin embargo, en el empleo, solo representan el $21 \%$ de la 
fuerza laboral, lo que muestra las enormes dificultades que ellas tienen para insertarse en la profesión.

La autora distingue diferentes trayectorias familiares y educativas de las jóvenes que estudian carreras técnicas. Respecto de las historias familiares, encuentra que tienen padres técnicos o ingenieros o bien llevan sobre sus espaldas el peso de ambiciones frustradas de sus padres, quienes hubieran querido seguir estudiando, pero que por razones financieras o por fracaso escolar no pudieron hacerlo. También encontró casos de familias en movilidad descendente, portadoras de un deseo de recuperación a través del éxito de sus hijos e hijas.

Estas jóvenes y sus familias, a su vez, valoran los estudios científicos y se sienten capacitadas para ellos, aspirando a llegar lo más alto posible en sus estudios. Generalmente se trata de familias sin hijos varones, en las que las hijas ocupan el lugar del varón faltante. También encontró, aunque en menor medida, familias en las que fue la madre quien orientó fuertemente a la hija a los estudios, para que realice proyectos que ella no pudo llevar a cabo.

En Argentina son menos las investigaciones sobre la situación de las mujeres en carreras no tradicionales, pero es un tema que cobró interés en las últimas décadas.

Kinzer (citada por Bonder, 1991) publicó en 1973 un estudio sobre las mujeres profesionales de Buenos Aires, motivada por el hecho de descubrir la gran cantidad de mujeres profesionales que hay en Argentina en comparación con su país, Estados Unidos, tanto en carreras neutras como masculinas", proponiéndose "mostrar que las mujeres profesionales de Buenos Aires pueden servir de modelos para las feministas norteamericanas". Sin embargo, la autora afirma que "la mujer médica e ingeniera que hace una carrera, si bien puede ser vista como una mujer no conformista por la sociedad argentina, es en realidad una hija obediente que sigue los mandatos de sus padres "..3

Para Pravaz (1992) también el trabajo y fundamentalmente el trabajo profesional de las mujeres "es en Buenos Aires, ciudad industrial moderna y anónimamente anómica, pero en la que el peso de la familia es sumamente importante, un mandato familiar". La autora pone el mayor peso de este mandato en las madres, ya sea la mamma italiana, la madre española o la mame judía (rusa y centroeuropea). En una ciudad donde el peso de la inmigración europea es tan importante, todas estas madres "han juntado sus influencias configurando un modelo central, definido y decisivo en la constitución de la

\footnotetext{
${ }^{2}$ Las carreras pueden considerarse masculinas, femeninas o neutras, teniendo en cuenta dos aspectos: el cuantitativo, que alude a las proporciones de estudiantes según el sexo (las que tienen más del sesenta por ciento de estudiantes varones son masculinas; femeninas, las que tienen más del sesenta por ciento de estudiantes mujeres y neutras, aquellas que tienen porcentajes similares de matriculación de ambos sexos) y un aspecto cualitativo, que alude a que la carrera está significada para uno y otro sexo o bien indistintamente para ambos. Ingeniería Agronómica e Ingeniería Industrial son carreras con una alta proporción de estudiantes varones y están fuertemente significadas como masculinas.

${ }^{3}$ Notemos la similitud del planteo de Kinzer con el de Daune Richard, aunque ambos estudios se refieran a contextos disímiles como Buenos Aires y Francia.
} 
estructura de la mujer argentina y sus consecuencias en la identidad de la mujer" (Pravaz, 1992).

Para la autora, las jóvenes universitarias argentinas, hijas mayoritariamente de la inmigración, provenían de familias en las que el modelo materno era fuerte, y supo lograr en sus hijas una alta valoración de la educación como base de la movilidad social. Estas jóvenes tenían "dos alternativas: parecerse a la madre existente o parecerse a lo que la madre debería haber sido como aspiración de deseos para su hija (ideal de yo)".

Otra línea de investigación aborda la relación entre educación y trabajo profesional (entre otros Llomovate, 1986; Riquelme y Fernández Berdaguer, 1990; Alfei, Crespo y Sigall, 1998; Fernández, 1994; García Frinchaboy, 1986).

Dos trabajos abordan el tema del trabajo profesional de las ingenieras agrónomas: Súarez y Canaves, 2000 y Bocchicchio, 2003). Suárez y Cánaves realizan su investigación con ingenieros agrónomos de ambos sexos graduados en la Universidad Nacional del Litoral. Las ingenieras entrevistadas afirman que el ejercicio profesional en el campo es bastante incompatible con la maternidad, sobre todo debido a que al tiempo de trabajo se debe sumar el tiempo de traslado, lo que incrementa la cantidad de horas que debe dedicarse a la actividad laboral. Ellas reconocen tener mayores dificultades para conseguir empleo que sus compañeros. Muchas se encontraban trabajando en la docencia, pero destacaban que estaban en cargos más bajos que sus compañeros varones.

Las autoras afirman que:

"Por disponer sólo de un título no está asegurado el ingreso laboral. La pertenencia social, las características de la familia, la socialización, la posición política cuentan cuando se trata de buscar empleo. Si esto es asi en todas las profesiones, no sería distinto para la ingeniería agronómica. El ingreso esta carrera por parte de las mujeres no parece tener a tener relación directa con la feminización de algunas actividades sociales ni con las reivindicaciones propulsadas por los movimientos de mujeres, pero sí se relaciona con la socialización en un medio rural desde la infancia.

La discriminación en el ejercicio profesional es percibida por ellas. Esta suerte de exclusión no se justifica con la diferencia cultural. El cambio en los mandatos sociales, el fin de la monopolización de la función de proveedor por parte de las mujeres (en lugar de guardar el título y de dedicarse a la domesticidad) son evidentes tanto en las encuestas como en las entrevistas. Las mujeres profesionales hoy deben ejercer como tales, a diferencia de años atrás, y ya no están sólo en las tareas tradicionales... Las profesionales están pareciéndose a los varones en su trayectoria profesional, 
principalmente las solteras, y los varones están participando más de la unidad doméstica que antes".

En esta investigación se encontró también que las ingenieras agrónomas están satisfechas con su ejercicio profesional, a pesar de que afirman que les cuesta más conseguir empleo y ganan menos que sus compañeros.

Rodríguez Giles, Colombo y Delgado (1994) realizaron un estudio comparativo de ingresantes de ambos sexos a la carrera de ingeniería de la Universidad Nacional de La Plata, a pedido de la misma universidad, e intentando dar respuesta a la constatación de que las graduadas de las distintas ramas de las ingenierías no trabajaban en la profesión y cuando lo hacían, se dedicaban mayoritariamente a la investigación o la docencia.

Las autoras señalan que la investigación realizada mostró "que las mujeres que eligen la carrera de Ingeniería se caracterizan por no desertar de sus estudios y en general, ser excelentes alumnas; sin embargo, una vez licenciadas rara vez ejercen su profesión. Esta situación parece evidenciar algún tipo de conflicto vinculado con las motivaciones en la elección de la carrera y/ o con su posterior opción laboral y desarrollo profesional".

Como hemos visto hasta aquí, estos resultados no coinciden con los de otros estudios en los que se muestra que si bien las mujeres ingenieras tienen más dificultades para la obtención del trabajo y para el ejercicio profesional, trabajan en la profesión. Las autoras afirman que las graduadas entrevistadas se caracterizan porque "en algunas de ellas la elección de carrera no estuvo necesariamente vinculada a su futuro papel profesional del que en general no tenían demasiado conocimiento, sino la búsqueda de autoafirmación y reconocimiento social por elegir una de las licenciaturas consideradas más difíciles y a las que sólo los hombres acceden. En otros casos, la elección estuvo vinculada a expectativas profesionales no realizadas por sus padres. Un dato significativo es que el 60 \% son hijas únicas o hijas mayores de familias donde el resto de los hijos son del sexo femenino".

En una investigación (Palermo, 2005) en la que indagamos las características básicas, las trayectorias educativas y ocupacionales previas, las motivaciones y expectativas vinculadas con la elección de la carrera y las concepciones de género de los estudiantes de ambos sexos que están cursando carreras "masculinas" y carreras "femeninas", encontramos resultados similares en relación con la elección de carrera, ya que mientras los estudiantes varones de las ingenierías afirmaban que habían elegido la carrera motivados por el futuro profesional y muchos de ellos ya estaban vinculados de alguna manera con la carrera, ya sea por estudios secundarios o trabajos relacionados, o porque el padre o algún familiar son ingenieros, las jóvenes manifestaron haber elegido ingeniería por la formación que esta brinda, por el interés en materias como física o química o porque les gusta la orientación, sin mencionar el futuro profesional. 
Eran muy pocas las que habían cursado secundarios relacionados, y ninguna trabajaba en espacios laborales afines. La mayoría de los estudiantes, con independencia del sexo, considera que se trata de una carrera en la que los varones tienen más ventajas en el ejercicio profesional y reconocen diferentes espacios laborales para ambos sexos. Mientras que los estudiantes tienden a justificar estas diferencias por "las diferentes cualidades" de las mujeres y de los varones y porque "el rol prioritario de las mujeres es el maternal", las jóvenes tienden a denunciar estas diferencias como discriminatorias, aunque también la mayoría prioriza el rol maternal por sobre el profesional, considerando que cuando tengan hijos deberán conciliar ambos roles.

La ingeniería está significada en el discurso de los estudiantes de ambos sexos, pero sobre todo en el de los varones, como una carrera dura, difícil y prestigiosa, como una carrera de "hombres", en la que prevalece lo técnico, asociado al ideal de masculinidad. Las jóvenes que hemos entrevistado se sienten seguras de sí mismas y capaces de llegar a buen término en la carrera elegida. Menos seguras están cuando piensan en su futuro profesional. La elección de una carrera no tradicional por parte de las mujeres provoca un alto grado de incertidumbre sobre su futuro profesional, lo que las lleva a reducir sus expectativas, ya que: a) genera dudas acerca del logro de objetivos profesionales (relación esfuerzos éxito), b) no permite anticipar la obtención de resultados como consecuencia de su logro (relación éxitos resultados) y c) no permite valorar los resultados que espera conseguir. ${ }^{4}$

Ante estos resultados, cabe preguntarse por qué las jóvenes eligen ingeniería si son tan conscientes de las discriminaciones que probablemente se enfrenten en el ejercicio profesional. ¿Se puede hipotetizar que si eligen la carrera, a pesar de la conciencia respecto de estas discriminaciones, estarán dispuestas a enfrentarlas en el ejercicio profesional? Para responder a estos interrogantes, es necesario que consideremos a la elección de carrera como una etapa del proceso de profesionalidad, tema que veremos en el próximo título.

\section{La profesionalidad como proceso}

El ingreso en una carrera universitaria es una instancia crucial de este proceso de profesionalidad, que es entendido por Hualde (2000) como un "concepto multidimensional en el que se integra la dependencia de un salario (o no), el conjunto de conocimientos o habilidades que se emplean y se aprenden, las características propias de las organizaciones y la consideración social acerca de la profesión" (Hualde, 2000: 674).

\footnotetext{
${ }^{4}$ Estamos aquí dialogando con la teoría de las expectativas, para la cual la fuerza motivacional de una conducta es mayor en la medida en que el individuo es capaz de conseguir lo que se propone (relación esfuerzo-éxito), cree poder obtener ciertos resultados como consecuencia de su logro (relación esfuerzos resultados) y valora los resultados que espera conseguir (véase Kornblit, 1996).
} 
En el proceso de profesionalidad, en el cual la elección de la carrera es una instancia clave, tienen un lugar relevante el saber y el saber hacer (competencia y habilidades técnico profesionales) y el saber ser (competencias adquiridas a través de distintas experiencias, familiares, escolares y del medio social). La profesionalidad se va construyendo a lo largo de la vida de una persona, a través distintas instancias: los juegos infantiles, las imágenes que los niños/as se hacen de su futuro ${ }^{5}$, las primeras relaciones de identificaciones con figuras representativas de su entorno familiar y social y la trayectoria educativa, la elección de la carrera, la formación recibida, la graduación, el ejercicio profesional, la capacitación, las distintas modalidades de ejercicio profesional, etc.

Testa (1996); Testa, Palermo (1998); Testa, Sánchez (2005) afirman, en este sentido, que esta profesionalidad se materializa a partir de las trayectorias socioeducativas en el ámbito del sistema formal de educación y de las trayectorias socioprofesionales en los ámbitos del desempeño laboral.

Panaia y otros (2003) se centran en la carrera en el trabajo. Afirman que "las carreras no constituyen más las vías regias de movilidad en el mercado de trabajo que habian representado durante los períodos de mayor expansión económica de los países desarrollados y de muchas de las economías emergentes. Actualmente sus condiciones de desarrollo están afectadas por la lentificación del crecimiento económico, la depresión del crecimiento de la industria, como uno de los sectores más afectados por la crisis del empleo de los ochenta y las estrategias empresariales que han adoptado las empresas. Si el concepto de carrera en el trabajo se mantiene sólo como una característica de los sectores protegidos y además en éstos la práctica del de layering es habitual para disminuir las cuotas de poder, es necesario focalizar algunos análisis en las formas de promoción social en el trabajo y cuáles son sus correlatos con el antiguo criterio de carrera en el trabajo".

El análisis de las trayectorias de los graduados en ingeniería significa para los autores analizar tres momentos significativos: el acceso al empleo con posterioridad a la graduación; el momento en que las trayectorias se quiebran, como estudiantes o como trabajadores y el tramo interno a una misma empresa o tipo de empresa que mantiene una cierta continuidad en el tiempo.

Si bien la trayectoria laboral truncada o con frecuentes bifurcaciones es, según los autores, el escenario más frecuente de la carrera del ingeniero tecnológico en Argentina, "más limitada aún es la posibilidad de inserción de la mujer ingeniera, frecuentemente descalificada en sus conocimientos y capacidades de mando por su género" (Panaia y otros, 2003).

\footnotetext{
${ }^{5}$ Naville (1975) habla de la existencia en el niño de una "ilusión profesional", que es la representación que este se hace de un oficio antes de haber podido tomar contacto efectivo con él. Posteriormente, esa ilusión sufre una crisis, a través de la cual los jóvenes adquieren su conciencia y su práctica adulta de un oficio.
} 
La noción de trayectorias educativas y laborales parte de una visión del papel que juegan "las trayectorias educativas, que comenzaron en la más temprana edad, en una secuencia que va desde la formación inicial hasta la universitaria, pasando por la primaria y la secundaria" (Testa, Sánchez, 2003) en la inserción laboral de los graduados universitarios y por consiguiente en la profesionalidad. En esta trayectoria, la credencial universitaria tiene un peso determinante.

La construcción de estos itinerarios educativos se enfrenta con diversos obstáculos (falta de articulación entre niveles educativos, segmentación y diferenciación del sistema educativo, entre otros). En el caso de los estudiantes de distinto sexo de carreras técnicas las trayectorias educativas devienen un aspecto clave a considerar, por el hecho de que en las mujeres estas trayectorias están caracterizadas por el quiebre más que por la continuidad, lo que se traduce para ellas en un obstáculo adicional.

Por otra parte, hay investigaciones que muestran que los itinerarios profesionales y los estilos de profesionalización que desarrollan las mujeres difieren del de los varones. En el próximo título consideraremos estas especificidades.

\section{El proceso de profesionalidad de las mujeres}

Wainerman y Navarro (1979), al estudiar el comportamiento laboral de las mujeres, afirman que tanto su monto como su estructura están en relación con los valores que rigen la conducta de ambos sexos; existe, así, "una dimensión normativa de la cultura que regula las relaciones entre el rol doméstico y el rol económico de la mujer. Esta dimensión normativa está compuesta por los valores culturales, que si bien nutren y ejercen un efecto coercitivo sobre las orientaciones valorativas, actitudinales y motivacionales de los miembros de la sociedad, son anteriores y no coinciden con dichas orientaciones". Estas consideraciones son válidas no solo para analizar el comportamiento laboral, sino también las elecciones profesionales de las mujeres.

De este modo, en el camino hacia la profesionalización, ellas se enfrentan con una serie de decisiones vinculadas con las definiciones culturales de género. Si bien tener mayor nivel de instrucción lleva a las mujeres a participar más en el mercado de trabajo si las comparamos con aquellas con menor nivel de instrucción, y a manifestar un comportamiento laboral semejante al de los hombres (Wainerman, 1979; 2002; 2005), no todas tienen el mismo comportamiento una vez obtenido su título universitario.

Mónica Frinchaboy (1988), al analizar datos sobre el nivel de instrucción de las mujeres y el acceso al mercado de trabajo, afirma que esos datos no nos dicen nada acerca de sus modalidades de participación laboral. Muchas profesionales, cuando se casan y tienen hijos pequeños, alteran el modo de inserción laboral sin abandonar el ejercicio de su profesión. De esta manera, concilian los roles de profesional y ama de casa reduciendo el número de horas que dedican al trabajo remunerado. Este hecho tiene consecuencias en 
la profesionalización debido a que se resiente la posibilidad de capacitación y progreso profesional.

Gloria Bonder afirma que muchas mujeres acceden a la universidad con la sola expectativa de obtener un título, ya que "el nuevo discurso social sobre la mujer moderna incluye a la educación superior como un atributo deseable para ellas" (Bonder, 1990).

La evolución de la imagen tradicional de mujer, confinada a los límites de su hogar y dedicada por completo a su papel de esposa y madre, pero con una progresiva aunque limitada incorporación en el mundo público, fue probablemente uno de los factores que provocaron el crecimiento sostenido de la matrícula universitaria femenina que se produjo a partir de 1941. Ana María Fernández (1994) señala a la década del 60 "como un momento de giro de las mentalidades familiares respecto al nivel de aspiraciones de instrucción de sus hijas". Son las mujeres de clase media las que acceden mayormente a los estudios universitarios. ${ }^{6}$ En un primer momento, esto se inscribe "dentro de las características del desarrollo de la educación superior en los países de América Latina donde las profesiones universitarias aparecen como uno de los canales de movilidad social y legitimación de las clases medias, es decir que el ingreso de las mujeres a la universidad es producto de una modificación de clase y no de género" (Fernández, 1994). Sin embargo, en la actualidad, como señala Bonder, la universidad argentina "no está ajena a los fenómenos sociales y culturales que acompañan la crisis por la que atraviesa el país..., los efectos de la crisis económica se hacen sentir en el mercado de profesionales a través del desempleo, la ocupación precaria y frecuentemente desvinculada de la formación universitaria recibida, así como también en la prolongación del tiempo de espera para el ingreso al primer empleo".

En este contexto, la posesión de un título universitario no garantiza ninguna movilidad social, sino que ha adquirido solo el valor de una credencial. Rosana Gambero (1995), al analizar las opciones que realizan los estudiantes al finalizar los estudios secundarios, encuentra que son las estudiantes mujeres las que tienen más clara su opción por estudios terciarios, mientras que los varones parecen tener más predisposición a inclinarse por ingresar al mercado de trabajo. La autora hipotetiza que estas opciones, en ambos sexos, parecen formar parte de estrategias familiares más que responder a opciones individuales de los mismos estudiantes.

En relación con la profesionalización de las mujeres, Bonder señala que es importante indagar acerca de los significados que tienen para ellas la obtención de un título universitario respecto de tres aspectos:

a) las expectativas familiares;

\footnotetext{
${ }^{6}$ Doris Klubitschko (citada por Cano, 1985), quien realizó un análisis del origen de los estudiantes de la Universidad de Buenos Aires en el período que estamos mencionando, afirma que "existe una mayor predisposición de los sectores medios a enviar a sus hijas a la universidad, en tanto que los estratos altos y bajos tienden a hacerlo en menor medida".
} 
b) el discurso social de la mujer y el sistema de género en la sociedad argentina;

c) las estrategias de supervivencia y de movilidad social de las mujeres de clase media.

Sabemos, por otra parte, que una vez recibidas, el comportamiento laboral de las mujeres difiere del de los varones. La posesión de un título universitario no implica necesariamente que ejerzan su profesión. Las que lo hacen desarrollan distintos comportamientos y estilos de profesionalización. El comportamiento y estilo laboral de algunas está íntimamente relacionado con las etapas de su ciclo vital (casamiento, nacimiento y crecimiento de los hijos). En cambio, otras desarrollan su profesión independientemente de dichas etapas (Fernández, 1994).

Esta última situación es cada vez más frecuente entre las mujeres en la actualidad, ya sean profesionales o no. Catalina Wainerman $(2002,2005)$ afirma que el proceso de feminización de la fuerza del trabajo ${ }^{7}$ que se produjo en nuestro país, primero lentamente a partir de 1950 y de modo más acelerado desde los 60, modificó tanto la estructura como el volumen de la fuerza de trabajo de ambos sexos, generando un cambio de carácter revolucionario, ya que fueron las mujeres adultas, casadas o unidas, las que en mayor proporción incrementaron su participación en el mercado de trabajo, permaneciendo muchas de ellas en él independientemente de su situación familiar.

Por otro lado, si bien las mujeres con mayor nivel de instrucción tienen más participación en el mercado de trabajo que aquellas con menor nivel de instrucción (Wainerman, 1979; 2002; 2005), esto no implica que tengan las mismas oportunidades ocupacionales que los varones, que son los que ocupan los puestos de mayor jerarquía y obtienen mejores remuneraciones.

Las características y modalidades de la participación femenina en el mercado de trabajo están relacionadas con una multiplicidad de variables, estas no solo dependen de las condiciones del mercado en cuanto a la demanda, sino que desde la perspectiva de la oferta aparecen determinadas características que les otorgan un nivel específico. Suele considerarse que estas características están ligadas a su ciclo vital y al modo como articulan el rol de esposa y madre con el de profesional (Fernández, 1994).

Desde la perspectiva de las propias mujeres (oferta), en consecuencia, podemos distinguir factores objetivos y factores subjetivos, muchos de los cuales están presentes y seguramente son tenidos en cuenta desde el momento de elección de una carrera universitaria. Entre los factores objetivos se encuentran el casamiento, el nacimiento y cuidado de los hijos y otros eventos del ciclo vital, así como las definiciones culturales relativas al género. Entre los factores subjetivos mencionaremos las expectativas sociales, parentales y personales acerca del desempeño de una profesión, los perfiles profesionales

\footnotetext{
${ }^{7}$ Wainerman (2002) denomina a este proceso "movimiento de la casa al trabajo".
} 
esperados para ambos sexos, las opiniones personales respecto de la vinculación de la carrera elegida con un determinado sexo, la percepción acerca de la compatibilización entre el rol profesional con el de ama de casa y madre que, de alguna manera, expresarían las definiciones culturales al género, antes aludidas.

En una investigación realizada con mujeres psicólogas (Fernández, 1994) se encontró que ellas desarrollan dos modos distintos de profesionalización: altamente profesionalizadas y con escasa profesionalización, y que esos estilos no están relacionados únicamente con características objetivas sino con factores subjetivos. Las primeras no hacen depender su desempeño profesional de las etapas de su ciclo vital; aquellas que desarrollan escasamente su profesión, en cambio, lo hacen cuando desaparecen determinadas condiciones objetivas por las cuales permanecían mayor tiempo en el hogar, por ejemplo, hijos pequeños que han crecido (Fernández, 1994).

Sin duda, identificar las modalidades de transición profesional, es decir, los modos mediante los que se construye la profesionalidad (Casal Bataller, 1999) puede ayudarnos a comprender las dificultades que encuentran las jóvenes en la vida adulta.

\section{Las modalidades de construcción de la profesionalidad o itinerarios profesionales}

Casal Bataller (1999) afirma que las investigaciones sobre los itinerarios de transición posibilitan pensar que estas diferentes modalidades se estructuran a partir de dos ejes. El primero, "muy complejo, identifica los procesos de generación de expectativas y de ajustes con relación a los logros. Reúne las distintas alternativas de transición posibles que los jóvenes pueden afrontar: definir una escolarización larga y prolongada, contra la escolarización mínima, definir un campo de elevadas expectativas en cuanto a la elección de carrera o bien optar por ocupaciones sin cualificación, diferir o avanzar el proceso de autonomía económica, etc. De hecho nos encontramos ante un conjunto de variables convergentes hacia la idea de construcción del horizonte social y la proyección del futuro... el segundo eje, mucho más mensurable, recoge el conjunto de variables de tiempo, es decir, el tiempo en que los jóvenes asumen objetivos significantes en relación con la transición: una inserción laboral relativamente precoz versus una inserción retardada, un acceso rápido a situaciones de autonomía económica versus la prolongación de situaciones de dependencia, una proyección muy definida hacia la emancipación familiar versus la búsqueda de formas de vida en pareja congruentes con la dependencia familiar, etc".

Las combinaciones de estos dos ejes permiten identificar seis modalidades de transición: 
1) trayectorias en éxito precoz, que implican itinerarios de formación académica prolongada, con altas expectativas de logro, sin rupturas y con tránsito positivo y exitoso a la vida adulta;

2) trayectorias obreras, que refieren a una profesionalización "a pie de obra", orientada a las opciones de empleo existentes, generalmente de trabajo manual y poco cualificado, que no representan opciones personales de elección profesional. Se trata de trayectorias vulnerables a los cambios en el mercado de trabajo y con límites impuestos por la baja cualificación;

3) trayectorias de adscripción familiar, que presupone un horizonte de clase en función de la familia y un tránsito a la vida activa precoz en tanto el joven queda inmediatamente vinculado con la economía familiar;

4) trayectorias de aproximación sucesiva, son transiciones de ensayo y error, con un retraso en la asunción de logros en la carrera profesional y en la emancipación familiar, propios de personas con altas expectativas de logro profesional, pero en un contexto en el cual las opciones a tomar resultan difíciles o confusas. Esta modalidad se caracteriza por un ajuste continuo de las expectativas y logros parciales escalonados;

5) trayectorias de precariedad, que se definen por itinerarios escasamente positivos respecto del mercado de trabajo, de ausencia, de estabilidad y continuidad, lo que obliga a un retraso respecto de la opción de emancipación familiar;

6) las trayectorias de bloqueo o desestructuración, se caracterizan por un bloqueo sistemático ante la inserción laboral, paro crónico o entradas circunstanciales en el mercado de trabajo.

La crisis económica actual y los altos niveles de desocupación han provocado cambios en las modalidades de transición de los y las jóvenes. En este contexto, la modalidad predominante entre los/as profesionales es la de aproximación sucesiva. Los itinerarios formativos, en estos casos, están condicionados por los logros académicos, por las posibilidades personales de acceder a las ofertas formativas y a la cada vez más difícil toma de decisiones ${ }^{8}$ con relación a la elección de la carrera.

Uno de los riesgos de esta modalidad es que los/as jóvenes tomen decisiones incongruentes, lo que los lleva a una falta de coherencia en el proceso de profesionalidad, que redunda en mayores dificultades en la construcción de la profesionalidad.

\footnotetext{
${ }^{8}$ Uno de los aspectos que dificultan la toma de decisiones es la diversificación de la oferta universitaria.
} 
El escenario actual se torna complejo por la crisis económica que obliga a los jóvenes a retardar el proceso de autonomización familiar (Casal Bataller, 1999) o de implementar formas intermedias de relativa autonomía. ${ }^{9}$

Si bien la profesionalización es un proceso continuo, en este artículo nos centramos en la etapa de la carrera universitaria. En esta etapa cobra importancia lo que se denomina transición de los y de las jóvenes a la vida adulta, sobre todo en lo que se relaciona con las variables convergentes hacia la construcción de un horizonte social y la proyección al futuro.

El escenario de crisis provoca en los y las jóvenes una alta incertidumbre frente al futuro laboral. Como hemos visto a lo largo de nuestra investigación, en el caso de los estudiantes de carreras técnicas, esta incertidumbre es mayor en las jóvenes. Si la construcción de imaginarios profesionales y la transición profesional constituye hoy uno de los campos más difíciles en la toma de decisiones, y la posibilidad de posponer decisiones o de tomar decisiones por inercias sociales es alta (Casal Bataller, 1999), pudimos observar que lo es más todavía en las jóvenes que estudian carreras no tradicionales.

Hay, sin embargo, un aspecto entre lo que señala Casal como riesgo para los jóvenes de la actualidad en el que las estudiantes de carreras no tradicionales parecen aventajar a sus compañeros, y es en la construcción de imaginarios o expectativas profesionales más ajustadas a la realidad. Si los jóvenes corren el riesgo de construir imaginarios profesionales desajustados con relación a los problemas reales, esto claramente no ocurre en las estudiantes de ingeniería de nuestra investigación, las que parecieran realizar un análisis evaluativo constante y una confrontación de sus propios deseos y metas profesionales con la discriminación que perciben claramente en el ámbito profesional.

En este sentido, si la incertidumbre está más relacionada en ellas con el hecho de ser mujeres que con la crisis actual del país, en sus proyectos profesionales parecen construir expectativas o imaginarios profesionales más cercanos a las reales posibilidades de acceso laboral, ya que en la construcción de su imaginario profesional van internalizando las discriminaciones que perciben en el ámbito profesional.

\footnotetext{
${ }^{9}$ Los procesos de autonomización de los y las jóvenes respecto de las familias son un fenómeno relacionado con el surgimiento de la familia moderna. Shorter (1997) plantea que es con la Revolución Sentimental de los años 60 cuando se inician los procesos de destutelarización de los padres respecto de las elecciones de vida de sus hijos e hijas, entre ellos la elección profesional, relacionados con la pérdida de autoridad del padre en la familia. Sin embargo, como señala Fernández (1994), "en las clases medias argentinas cuando ya había cobrado consensualidad la libertad de elección de vida de los hijos varones, todavía permanece varias décadas más la idea de las hijas mujeres como ciudadanas en situación de tutelaje, en primer lugar del padre, y luego del marido". La autonomización requería determinadas condiciones socioeconómicas, que permitieran a sus hijos e hijas asumir las consecuencias económicas de sus elecciones.
} 


\title{
Las significaciones de las estudiantes de Ingeniería respecto de sus proyectos profesionales
}

\begin{abstract}
"Carrera muy poco tentada aún por las mujeres, y que realmente no es de las más apropiadas para su sexo, es la de Ingeniería".
\end{abstract}

Elvira López (1901)

"El Ingeniero no se inventó para las mujeres, dicen"

(Sara, 23, $2^{\circ}$ año)

Ha pasado un siglo desde que Elvira López, en su tesis para recibir el grado de Doctora en Filosofía y Letras, escribía lo que citamos en el primer epígrafe y esa afirmación parecería seguir vigente hoy. Las estudiantes que actualmente cursan las carreras masculinas ${ }^{10}$ son pocas, y una de ellas, en el segundo epígrafe confirma, a poco más de un siglo, la opinión de Elvira López.

El hecho de que el primero corresponda a una aspirante a doctora en Filosofía y Letras y el segundo a una estudiante de Ingeniería Agronómica aparece matizando una diferencia en las opiniones vertidas por ambas. Si para Elvira López la carrera, además de ser poco tentada para las mujeres es también poco apropiada para ellas, la estudiante pone su afirmación en el afuera: no soy yo la que opina eso, lo "dicen", ya que a ella la tentó la carrera.

Sin embargo, a lo largo de nuestra investigación, hemos podido comprobar que estas estudiantes tienen claro que, tanto en las opiniones de la sociedad, así como en el ámbito laboral, y más cerca aun, en el "clima que viven en la universidad", la carrera de Ingeniería "se ha inventado para los hombres", como afirma nuestra entrevistada.

Si bien la lógica de elección de la ingeniería se basó más en factores relacionados con la formación que la carrera les brindaba que con el ejercicio profesional, las estudiantes de Ingeniería Agronómica afirman que les gusta trabajar "en el campo" y las de Ingeniería Industrial en la "planta de una industria", al igual que sus compañeros

\footnotetext{
${ }^{10}$ Las estudiantes entrevistadas corresponden a Ingeniería Agronómica y a Ingeniería Industrial de la Universidad Nacional de Luján, Argentina. La investigación realizada tuvo dos etapas: una primera cuantitativa en la que indagamos estudiantes de ambos sexos de carreras masculinas y carreras femeninas. La segunda etapa fue cualitativa y se centró en las estudiantes mujeres de carreras masculinas. El carácter cualitativo de estas entrevistas no nos permite generalizar, pero nos ha permitido construir conceptos cercanos a los datos. Uno de estos conceptos es el de estrategias anticipatorias de su inserción profesional, que exponemos en este artículo.
} 
varones. Pero a medida que avanzan en la carrera sienten cada vez más lejana la posibilidad de trabajar en lo que les gusta:

"¿Qué pienso?... y la inserción laboral al no tener ningún reconocimiento previo de la actividad, y aparte ser mujer, te va a limitar a conseguir trabajo".

(Liliana, $21,2^{\circ}$ año)

"Ante un currículum similar, vamos a poner un caso concreto, entre un hombre y una mujer, tal vez prefieran al hombre, creo que esa limitación y en determinados sectores del espectro laboral que puede llegar a haber".

(Agustina, 24; $5^{\circ}$ año)

Un dato relevante es que el nivel de satisfacción que estas jóvenes tienen con la carrera baja a medida que avanzan en ella. Las ingresantes están todas satisfechas con la elección de ingeniería y en cambio, al llegar al último año de cursada, solo la mitad de ellas lo está. En este cambio juega el nivel cada vez mayor de conciencia que van teniendo acerca de las dificultades y de las discriminaciones respecto de las mujeres en el ejercicio profesional. Este mayor nivel de conciencia las lleva a elaborar estrategias para intentar superar esas limitaciones. En el próximo título nos ocuparemos de un concepto que hemos construido en nuestra investigación a la luz del análisis de los datos y que nos ayudará a comprender los proyectos que las jóvenes de las ingenierías van elaborando en relación con su futuro profesional.

\section{Estrategias anticipatorias de la futura inserción profesional}

Las estrategias anticipatorias del futuro profesional son proyectos de trayectorias profesionales o imaginarios profesionales dirigidos a alcanzar una meta determinada, que se elaboran a partir de un análisis evaluativo en el que se imbrican los propios deseos e intereses sobre el desarrollo profesional y el nivel de conciencia que las jóvenes de carreras no tradicionales van adquiriendo acerca de las dificultades existentes para el logro de dicha meta. Estas dificultades van más allá de las que podrían enfrentar los graduados universitarios en la obtención de un trabajo relacionado con su profesión y en la carrera profesional, ya que a ella se incorporan dificultades específicas por ser mujeres, como pudimos ver en lo que nos relataban en el título anterior dos de las estudiantes entrevistadas. ${ }^{11}$ Estas estrategias forman parte de la construcción del imaginario profesional (expectativas profesionales).

\footnotetext{
${ }^{11}$ Es interesante aclarar que los varones, ya sea que estudien carreras tradicionales como no tradicionales para su sexo, limitan las dificultades que podrían tener en su carrera profesional a la situación social y económica del país, pero consideran, según palabras de un entrevistado, "que por el solo hecho de ser hombres, tenemos mayores posibilidades
} 
Encontramos cinco modalidades de estrategias anticipatorias en las estudiantes de carreras no tradicionales:

a) Las estrategias orientadas a la colaboración familiar priorizan, en las expectativas sobre el futuro profesional, la elaboración de un proyecto familiar profesional o la inserción en un proyecto familiar ya existente (trabajar en la industria del padre u otro familiar, formar una empresa familiar, etc.). Se trata de un proyecto en el cual la elección de carrera está vinculada con expectativas o proyectos familiares y cuyas expectativas se relacionan también con lo familiar. Se trata de un círculo que se inicia y se proyecta hacia lo familiar, con conciliación entre proyectos familiares y profesionales, con énfasis en los primeros.

"Quiero ayudar a sacar adelante la industria de mi papá, que como ya te dije, estuvo mucho tiempo cerrada y ahora abrió. Yo colaboro y cuando estoy en clases, siempre presto atención a lo que me va a servir... entonces yo por eso me incliné a eso, y bueno, otra posibilidad, otra oportunidad".

(Bárbara, 24; $4^{\circ}$ año)

"Espero de mi profesión tener una casa, tener un perro, tener un auto, tener una familia. ¿Voy a llegar a ser gerenta? No, la verdad que no, bueno, capaz... entonces mi meta es una familia, la continuidad de una familia".

(Ana Clara, 25; $5^{\circ}$ año)

Estas jóvenes se sintieron apoyadas por su familia en la elección de la carrera y se sienten capaces de llevarla adelante porque tienen una trayectoria de buen

\footnotetext{
laborales". Los que estudian carreras en los que ellos son mayoría, como la ingeniería, consideran sin lugar a dudas que ellos están en mejores condiciones que sus compañeras para el ejercicio profesional. Aluden a que la carrera les brinda una variedad de áreas profesionales en las que insertarse, en las que por sus cualidades y capacidad de mando (ya que "un obrero -o un peón de campo- no acepta que una mujer le diga lo que tiene que hacer"), o por su trayectoria educativa y laboral previa (más vinculada con la carrera elegida, ya que provienen mayoritariamente de escuelas técnicas afines, mientras que sus compañeras provienen mayoritariamente de bachilleratos) pueden conseguir un trabajo con más facilidad y con mejor salario y están en mejores condiciones para progresar en la profesión. Los varones de carreras no tradicionales (Lic. en Educación, Lic. en Nivel Inicial) también afirman estar en mejores condiciones que sus compañeras, ya que pueden ascender más rápidamente en la profesión. Por su parte, las jóvenes incorporan a las dificultades relacionadas con la situación económica y social del país, cuestiones relacionadas con su condición de mujeres en ambos tipos de carreras: tradicionales para su sexo y no tradicionales. Sin embargo, esto es aun más fuerte en el caso las segundas, que suman el peso de estar estudiando una carrera significada "para hombres".
} 
rendimiento académico en materias como matemática, física o química. Se sienten inclinadas hacia lo técnico.

"En una época iba a estudiar Profesorado de Educación Física porque me gustaba hacer deportes. Y mi mamá me dice: ¿estás segura? Para que mi mamá me diga a mí.. como que veía que iba a explotar un área mía que estaba allí, que sólo le faltaba el moñito para que explote. Y ahí me hizo pensar que deporte puedo hacer toda la vida sin hacer Educación Física. El tema es que me gusta hacer deporte, no por el sueldo ni por nada. Entonces me dije: mi mamá tiene razón".

(Paula, 25; $4^{\circ}$ año)

"En mi casa me dijeron elegí lo que quieras hacer, nosotros te vamos a apoyar siempre, siempre..., pero mi mamá me dijo, yo creo que no, deberías seguir ingeniería".

(Ana María, 22, 1er año)

"Y cuando pensé en bioquímica mi papá me dijo: la humanidad va a tener siempre que comer $y$ eso es verdad, y entonces ahí opté definitivamente" (esta joven cursa simultáneamente Ingeniería Industrial e Ingeniería en Alimentos)

(Ana, 23, $2^{\circ}$ año)

La elección de la carrera puede aparecer hacia fuera, hacia la sociedad, como un desafío, pero el significado que tiene dentro del entorno familiar no implica un desafío, una ruptura, sino un retomar o continuar con algo que de alguna manera está presente en la historia familiar. Estos resultados coinciden con la opinión de Kinzer (citada por Bonder, 1991), para quien la mujer que opta por una carrera no tradicional puede ser considerada por la sociedad como inconformista, pero es en realidad una mujer conformista que obedece los mandatos de sus padres.

Coinciden también con los resultados de Daune Richard (1995), quien encontró que algunas mujeres de carreras tradicionales en Francia se caracterizan por acceder a proyectos que los padres forjaron para ellas debido a que están cercanas a ellos emocionalmente.

b) Las estrategias orientadas a áreas feminizadas implica la internalización de discriminaciones en el ejercicio de la profesión elegida. La amplitud de áreas laborales se presenta como estratégica para conseguir un empleo profesional, 
ya que en determinadas áreas (trabajos de laboratorio, de oficina, etc.) de la profesión, las mujeres tienen menos dificultades que en otras.

"Las mujeres tenemos dificultades para realizar trabajo de campo muy cansadores"

(Lucía, 22, 3er año)

"Somos más aptas para trabajar en empresas como La Serenísima o para laboratorios y ellos, para el trato con hombres y con máquinas".

(Marta, 20, 1er año)

"La carrera de agronomía es un poco como de trabajo duro, porque el trabajo de campo normalmente requiere de fuerza, y es por ahí más rústico, que no sería el más adecuado para una mujer, pero sin embargo, la carrera tiene muchas alternativas, no necesariamente podés trabajar en el campo, podés trabajar en un laboratorio o en una oficina y en mil cosas más, y además está el machismo de que el hombre va a ser más aceptado por los campesinos, trabajando con ellos, era más común que eligiera esto el hombre".

(Marcela, 26, $5^{\circ}$ año)

Del discurso de estas estudiantes se desprende la aceptación de áreas laborales más "apropiadas" para las mujeres y de otras más "apropiadas" para los varones. Si bien reconocen las discriminaciones y el hecho de que la sociedad ve la carrera como más apta para los varones, su elección profesional no es significada como un acto de desafío ni de rebeldía ni como un enfrentamiento con esas concepciones.

c) Las estrategias en espiral son estrategias de logros parciales; se trata de trabajar "de lo que surja", en palabras de las entrevistadas, con el propósito de ir adquiriendo experiencia y obtener después trabajos más relacionados con lo que les gusta. Sin embargo, no siempre hay en ellas una expectativa de progresar en la carrera profesional en el sentido de obtener puestos de mayor responsabilidad, sino de lograr trabajos con los que se sientan más a gusto, que les brinden satisfacciones personales.

En esta tercera estrategia, la amplitud del campo profesional y la existencia de áreas laborales femeninas y masculinas son significadas como estratégicas en 
relación con las posibilidades de inserción laboral y aparecen como un piso, como una etapa inicial que puede en algunos casos "postergar hasta un futuro indefinido" enfrentarse con las barreras de género y ascender en la carrera profesional.

"Cambié muchas veces la rama en la que quería trabajar... y después dije no, cualquier trabajo, lo que venga..."

(Jorgelina, 22, 3er año)

"Empecé con mil expectativas y después vas cayendo en lo que es la realidad de lo que es la carrera, y es más difícil todo, pero mis expectativas eran estar en el campo... bueno, lo que yo tenía como ideal, trabajar en el campo, de estar en una huerta y estar con los productores, todo se modificó un poco... porque no es por ahí tan simple, hay por ahí muchos ingenieros y los trabajos que más abundan son los de oficina, que no son los más lindos".

(Agustina, 24; $5^{\circ}$ año)

(Agustina, 24; $5^{\circ}$ año)

Esta estrategia se va elaborando en la mente de las estudiantes a través de un análisis evaluativo en el que tienen en cuenta sus propios deseos sobre el futuro profesional y las reales posibilidades de alcanzarlos. Entra a jugar aquí lo que podríamos denominar criterio de realidad.

Dos aspectos intervienen en la elaboración de esta estrategia:

- el ir cambiando las expectativas laborales en un interjuego que implica reconocer la realidad y al mismo tiempo mantener, en la medida de lo posible, el deseo inicial de trabajar en lo que les gusta;

- el reconocimiento implícito y a veces explícito de "que hay imposición, hay puertas que no se pueden atravesar, es asi", que pone límites al deseo personal, a las expectativas iniciales y al desafío que implica tratar de atravesarlos.

d) Estrategias orientadas a áreas sociales. Estas estrategias son típicas de las estudiantes de ingeniería agronómica. Esta carrera tiene un aspecto social y otro técnico, y las estudiantes se vuelcan hacia lo social. Se trata de un proyecto profesional en el que lo técnico está al servicio de lo social: capacitar a pequeños productores, brindarles herramientas para que puedan aprender a 
trabajar cooperativamente. Implica un cambio respecto del rol tradicional del ingeniero agrónomo.

"Yo antes pensaba más fríamente así... sin la relación que tienen los ingenieros con los productores, con la gente, como que la veía más técnica y ahora me parece que tiene que ser más social... no quiero llenarme de plata ni nada de eso; sí logros sociales por ahí de mejorar esto... no sé, con todo lo nuevo que hay de Agroecología... de que no se contamine tanto que nos e extingan las variedades de las diferentes culturas, de los indios, de los campesinos, todo eso..."

(Sonia, 25, $5^{\circ}$ año)

"Es importante la parte social, el contacto con los productores, el saber relacionarse".

(Inés, 24, 3er año)

Esta orientación social de la carrera, que se acerca más a lo tradicionalmente considerado como femenino, les abre un nuevo panorama, en el cual tienen la posibilidad de acercarse a la profesión desde un lugar no tan técnico, no tan "duro". Les abre la posibilidad de acercarse al otro, de ayudar, de contribuir a un proyecto social, a un cambio. Se trata sí de una carrera técnica, pero también de una carrera social, con compromiso social y político. Es así como dentro de esta estrategia se perfila un subgrupo orientado a la búsqueda de un cambio social o político. Estas jóvenes tienen conciencia crítica y quieren aportar a un cambio social, aunque solo en algunas de ellas esta conciencia involucra el sistema de género. La elección aparece como un desafío, como una ruptura. En este subgrupo, hay jóvenes que identifican la discriminación y las barreras que tienen las mujeres en la profesión y tienen una actitud de ruptura de esas barreras.

"Yo creo que como es tan importante la parte social, si la mujer a pesar de ese machismo del que te hablo es capaz de romper las barreras, de pasar las barreras, y tiene mucha actitud social, yo la veo de igual a igual, todo depende de la personalidad de ella, si bien, son importantes los conocimientos y cómo te desempeñás en la carrera, en un examen, al final, creo que la parte social es un aspecto más importante aún".

(Sara, 23, $2^{\circ}$ año) 
"Hay un suprasistema político, económico y cultural organizado. O sea la cuestión política delimita o te limita. Y te planifica. Viene algo planificado para tu vida. El hecho de que vos, por ejemplo, pertenezcas a determinada clase social, o a otra, de alguna manera te está diciendo bueno o a esto o a esto, a otras no. Y a nivel mujer, también. O sea la educación que vos recibís en la sociedad es altamente machista. Tenemos la religión... no tengo nada contra la religión, soy religiosa en lo individual, pero sí tengo contra las religiones el hecho de que generan una conciencia sumisa del hombre y de la mujer, iojo! Me parece que es una herramienta más de opresión, tanto del hombre como de la mujer. A la mujer le toca un rol bastante más sufrido, digamos en lo que hace a la opresión. Es un rol mucho más sumiso, donde la mujer es dueña de hacer solamente en su casa. Porque ese es el rol de las mujeres. Después se empiezan a rebelar, empiezan a estudiar y a participar. Pero bueno, hay imposición, hay puertas que no se pueden atravesar, es así. Hay mujeres que aceptan el desafío de atravesarlos y hay mujeres que se conforman con lo que tienen".

(Sonia, $25,5^{\circ}$ año)

e) Estrategias de construcción de la profesionalidad en "crisis". Las jóvenes elaboran estrategias anticipatorias de inserción laboral para las cuales el título profesional no es necesario. El perfil profesional queda desdibujado, y esto las lleva a estar en crisis con la elección realizada.

"Antes sabía que quería trabajar en el campo, ahora tengo una visión un poco más amplia, ya sean organizaciones, campesinos u otra cosa así; lo único que me había puesto a pensar es que no quería terminar trabajando en una multinacional, eso seguro... brindarme bien con la sociedad, de que sirva, de que haga algo ¿Entendés? Con todo lo que sé o no, porque puede ser que después no me sirva lo que aprendí acá, pero hacer algo concreto... yo digo lograr algo para la comunidad, no para mí, pero no sé si tiene algo que ver con lo profesional, porque si no pudiera seguir Agronomía, busco otra carrera y ya está, digamos como para hacer algo también, no sé si es muy profesional lo que te quiero decir".

(Clara, 24, $4^{\circ}$ año)

"Veo que si quiero trabajar con los campesinos se necesita mucho laburo, cualquier laburo, y siendo agrónoma, siendo maestra, siendo lo que sea, además, ir con una carrera o no, ir siendo mentalmente con una cuestión de compromiso, ir a un cambio y laburar, ahí hay laburo de todo. Por eso hoy digo 
bueno, voy a seguir Agronomía pero, si vas a un lugar así, capaz que ni necesitás algo de Agronomía... Por eso te estaba diciendo que estoy en crisis con mi carrera. Porque yo digo, si capaz no la utilice o la utilice. ¿Por qué no me voy el año que viene?..."

(Sonia, 25, $5^{\circ}$ año)

\section{A modo de cierre: algunas reflexiones}

La elección de la carrera no es, de esta manera, el punto de arranque de un camino lineal que llevará a las jóvenes hacia el ejercicio de una determinada profesión, sino que es una etapa del proceso de construcción de la profesionalidad que, las más de las de las veces, está plagado de marchas y contramarchas, avances y postergaciones, expectativas y cambios de expectativas.

Este proceso se desarrolla en un contexto histórico, social, político, económico, familiar, racial, de clase, de género, etc., en un movimiento dialéctico y continuo entre nuestros deseos y expectativas y sus condiciones de posibilidad.

Como hemos visto a lo largo de este artículo, muchas estudiantes de una carrera masculina como Ingeniería, en la construcción de sus proyectos profesionales, así como en las significaciones que les otorgan a estos, se "acomodan anticipadamente" en áreas profesionales diferenciadas según sexo y "asumen" como "propios" límites en su futura carrera profesional. Ante el hecho de haber elegido una carrera "masculina", que podría poner en duda su femineidad, utilizan distintos "mecanismos restauradores" de esa femineidad. Solo unas pocas se plantean metas que podríamos considerar feministas.

Una pregunta clave en este artículo refiere a los significados que tienen para las jóvenes la elección de una carrera no tradicional. Estamos inclinadas a pensar que estas jóvenes son tan inteligentes ${ }^{12}$ como las que eligieron carreras tradicionales, aunque la lógica que las lleve a elegir la carrera sea diferente. Para Daune Richard (1995), las mujeres que eligen carreras técnicas tienen una lógica más orientada a la formación que a la profesionalización. Por otra parte, en distintas investigaciones (Williams, 1989; Tiramonti, 1995; Rodríguez Giles, Colombo, Delgado, 1995, Suárez y Canaves, 2000, entre otros) se muestra que, una vez recibidas, las graduadas en carreras no

\footnotetext{
${ }^{12}$ Recordemos que Brush (1991) considera que las jóvenes que no optan por carreras científicas y tecnológicas podrían tener un comportamiento mucho más inteligente que aquellos que quieren promover por parte de ellas elecciones no tradicionales sin considerar los reales obstáculos que tienen durante sus estudios y su trabajo profesional.
} 
tradicionales se insertan profesionalmente en la docencia universitaria o en ramas feminizadas de su profesión.

Christine Williams (1989) considera que esto forma parte de un mecanismo por el cual las personas en carreras no tradicionales tienden a reafirmar su propia identidad de género. En efecto, para la autora, el hecho de trabajar en profesiones altamente generizadas en las que se encuentran formando parte de una minoría, provoca conflictos con la propia identidad femenina o masculina, que intentan resolver a través de mecanismos que las llevan a una reafirmación de su propia identidad. Como vimos en este artículo, varias de nuestras entrevistadas desarrollan lo que llamamos "mecanismos restauradores de la femineidad" ya en su posición de estudiantes de carreras no tradicionales.

No obstante, si consideramos que las discriminaciones respecto de las mujeres se dan en todo el ámbito profesional, ya sea con la misma existencia de carreras discriminadas según sexo como en el interior de una profesión (con las diferencias de áreas laborales, de posibilidades de progreso o de percepción de salarios), podemos decir que las mujeres en carreras tradicionales comparten con sus compañeras de carreras no tradicionales el hecho de sufrir discriminaciones. Difieren en que las primeras probablemente trabajarán en lo que eligieron, mientras las segundas sumarán a las discriminaciones comunes el tener que contentarse con trabajar en áreas laborales que no son aquellas por las que eligieron la carrera. Enfrentarán y tendrán que resolver ese conflicto, y como vimos, son conscientes de eso. Muchas de estas estudiantes seguramente abandonarán en el camino. Otras continuarán y obtendrán su título. En este artículo pudimos ver cómo la conciencia de estas discriminaciones está presente en la elaboración de estrategias anticipatorias de su futura inserción profesional.

Si comparamos el recorrido histórico del acceso femenino a la universidad (véase Palermo, 2006) con las elecciones no tradicionales que realizan las mujeres en la actualidad o con la ubicación en áreas de trabajo feminizadas cuando eligen una carrera no tradicional como la ingeniería, identificamos algunos puntos en común. Las primeras universitarias argentinas se enfrentaban con los estereotipos de género de la época al decidir estudiar en la universidad, pero elegían carreras y se ubicaban en ámbitos profesionales que no representaban una ruptura brusca con esos estereotipos. ${ }^{13}$

\footnotetext{
${ }^{13}$ El ingreso de las mujeres en la universidad implicó obstáculos de diversa índole, dependiendo en cada caso de la legislación de los países en cuestión. En Argentina, la primera mujer que quiso inscribirse en Medicina, Elida Passo (quien se había recibido de farmacéutica), tuvo que iniciar un recurso de amparo para ser aceptada en la carrera. Elida Passo falleció de tuberculosis antes de recibirse, por lo cual la primera graduada de una universidad argentina fue Cecilia Grierson, que se recibió de médica en 1889. Desde sus inicios, las elecciones femeninas fueron diferentes, acorde con una diferenciación socio-sexuada del saber. La mayoría de las primeras universitarias estudiaron carreras relacionadas con las ciencias de la salud, y especialmente Medicina, si consideramos carreras superiores. La educación médica empezó a verse, hacia fines de siglo XIX, como "apropiada" para las mujeres, quienes siempre habían sido las
} 
Una interpretación posible de estos hechos puede estar en que ellas interiorizaron los estereotipos de género. Sin embargo, también puede interpretarse que se trata de una estrategia que les permite aprovechar los intersticios que el sistema de género les deja, antes que enfrentarse abiertamente con él. Es decir, avanzan lo que pueden y hasta donde pueden, sin romper bruscamente con dichos estereotipos, ya que esto podría resultarles demasiado costoso.

El animarse a algo distinto las convierte de alguna manera en pioneras, hace que fijemos la atención en ellas y que constituyan modelos de identificación para futuras mujeres. Sin duda, esa no es su intención ni pensaron en ello al elegir su carrera

Un punto clave para considerar es hasta qué punto son conscientes de que están abriendo camino, hasta qué punto están dispuestas a luchar para hacerse un lugar en el ámbito profesional.

Estamos a favor de los que opinan que hay que seguir orientando a las chicas hacia las carreras científicas y técnicas. Pensamos que hay que distinguir entre el significado que tiene para ellas y el significado social que implica que estas jóvenes estudien una carrera no tradicional, ya que se convierten en figuras de identificación para otras mujeres, y a la vez, van cambiando las expectativas sociales sobre las carreras femeninas y masculinas.

Sin dejar de reconocer que "la revolución simbólica que reclama el movimiento feminista no puede limitarse a una simple conversión de las conciencias y de las voluntades" (Bourdieu, 2000: 58), quizás podríamos decir, parafraseando a Linda Birke (citada por Hammonds, 1996), que tal vez no se trate únicamente de incorporar mujeres en las carreras no tradicionales; tal vez se trate de generar en estas mujeres conciencia crítica. De allí la necesidad de planificar acciones, no solo para incrementar el ingreso de las mujeres en estas carreras, sino también de planificar espacios que estimulen esa conciencia crítica, que pongan el acento en la mujer como actora social.

supervisoras de la salud y las enfermeras del hogar (Gay, 1992). Posteriormente su elección se reorientó hacia Filosofía y Letras. En nuestro país, cuando se creó la Facultad de Filosofía y Letras de la UBA en 1986, se permitió a las maestras matricularse en ella sin ningún otro requisito. 


\section{BIBLIOGRAFÍA}

Alfei, B.; Crespo, G.; Sigal, V. (1992). Las carreras profesionales: hombres y mujeres en el mercado del trabajo. En Revista Propuesta Educativa, año 4, $n .^{\circ}$ 7, Buenos Aires: Miño y Dávila Editores.

Arango Gaviria, L. (2006). Jóvenes en la universidad. Género, clase e identidad profesional. Colombia: Siglo del Hombre Editores. Universidad Nacional de Colombia.

Bocchicchio, A. (2003). Inserción Profesional en las Ingenierías Agronómicas. Estudio de casos de los graduados recientes de la UBA. Ponencia presentada en el III Congreso Latinoamericano de sociología del trabajo El trabajo en los umbrales del siglo XXI. http://www.alast.org/PDF/Benencia/MyTR-Bocchicchio.PDF.

Bonder, G. (1991). Las mujeres y la educación en Argentina. En La mujer y la violencia invisible, Buenos Aires: Paidós.

Bourdieu, P. (2000). La dominación masculina. Barcelona: Editorial Anagrama.

Brush, S. (1991). Women in Science and Engineering. En American scientist. Volumen 79. Estados Unidos.

Casal Bataller, J. (1999). Modalidades de transición profesional y precarización del empleo. Edición en prensa, Germania, Alzira.

Cano, D. (1985). La educación superior en la Argentina. Buenos Aires: FLACSO, Grupo Editor Latinoamericano.

Daune- Richard, A. (1995). El ingreso de las mujeres en carreras "masculinas" de nivel técnico- superior. En Revista Calificaciones \& Empleo 6.

Duru Bellat, M. (1990). L'Ecolle des filles._Paris, L' Harmattan.

Duru Bellat, M. y Jarlegan, A. (2001). Garcons et filles a l'écolle primaire et dans la secondaire. En BLÖS, Thierry (sous la direction de) La dialectique des rapports hommesfemmes, Paris, PUF, pp. 73-78.

Elejabeitia Tavera, C. y López Saez, M. (2003). Trayectorias personales y profesionales de mujeres con estudios tradicionalmente masculinos. En Instituto de la Mujer, Ministerio de Trabajo y Asuntos Sociales. España.

Fernández, A. M. (1994). Mujeres profesionales ¿Conflicto de roles? de la tutela al contrato. En La mujer de la ilusión, Buenos Aires, Paidós.

Gambero, R. (1995). La articulación entre la educación media y la superior, Mimeo.

García Frinchaboy, M. (1981). Evolución de la participación universitaria femenina en Argentina (1940-1980), Buenos Aires, Departamento de Sociología. UCA.

-- (1985) Mujeres profesionales e inserción laboral, Buenos Aires, Editorial Prisma.

Gascón- Vera, E. (1995). La necesidad de una educación igualitaria de la mujer. En Martínez López, Cándida (editora) Feminismo, ciencia y transformación social, Granada, Feminae, Universidad de Granada, Instituto de Estudios de la Mujer. 
Gay, P. (1992). La experiencia burguesa. De Victoria a Freud tomos I y II, México, Editorial Fondo de Cultura Económica.

Hammonds, E. (1996). ¿Existe una ciencia feminista? En Ortiz Gómez, T.; Becerra Conde, G. (editoras). Mujeres de ciencias. Mujer, feminismo y ciencias naturales, experimentales y tecnológicas. Feminae. Universidad de Granada. Instituto de estudios de la mujer.

Hualde, A. (2000). La Sociología de las Profesiones. Asignatura pendiente en América Latina. En De la Garza Toledo, E. Tratado Latinoamericano de Sociología del Trabajo. México: Fondo de Cultura Económica.

Kornblit, A. L. (1996). Aportes de la Psicología Social a la problemática del trabajo en la sociedad argentina contemporánea. En Panaia, M. Trabajo y Empleo. Un abordaje interdisciplinario. Buenos Aires: Editorial EUDEBA, PAITE.

Llomovatte, S. (1986). Adolescentes trabajadores: su vida, escuela y trabajo. Documento de Trabajo N. ${ }^{\circ}$ 47. Buenos Aires: FLACSO.

López, E. (1901). El movimiento feminista. Tesis. Buenos Aires: Facultad de Filosofía y Letras. Imprenta Mariano Moreno.

Mosconi, N. (1998). Diferencia de sexos y relación con el saber. Buenos Aires: Facultad de Filosofía y Letras. UBA Ediciones Novedades Educativas.

NAville, P. (1975). Teoría de la orientación profesional. Madrid: Editorial Alianza.

Palermo, A. I. (2005). La profesionalización de las mujeres y varones. Informe final. Universidad Nacional de Luján.

(2006). El acceso de las mujeres a la educación universitaria. En Revista Argentina de Sociología. Año 4, N. ${ }^{\circ}$ 7. Argentina. Consejo de Profesionales en Sociología. Miño y Dávila, pp. 11-46.

Panaia, M. (1996). Introducción: Un estado de la cuestión sobre trabajo y empleo. En Trabajo y Empleo. Un abordaje interdisciplinario. Buenos Aires: Editorial EUDEBA, PIETTE.

Pravaz, S. (1992). Serás lo que debas ser o si no no serás nada: el trabajo como mandato. En Kohen, Beatriz (compiladora) De mujeres y profesiones. Buenos Aires: Ediciones Letra Buena.

Riquelme, G.; Fernández Berdaguer, L. (1990). La inserción de jóvenes universitarios en el mundo del trabajo. La relación estudio - trabajo y las expectativas sobre la vida profesional. Cuadernos de Investigación N. ${ }^{\circ}$ 2. Buenos Aires: Facultad de Filosofía y Letras - UBA.

Robles San Juan, V. y Anguita Martinez, R. (1995). La Universidad española desde la perspectiva de la incorporación de los alumnos: el pasado y presente de una desigualdad de género, en: Sanz Rueda, C. Invisibilidad y presencia. Seminario Internacional: Género y Trayectorias profesionales del Profesorado Universitario. Madrid: Universidad Complutense de Madrid. Dirección General de la Mujer. 
Rodríguez, M. M. (2000). Economía de la población y capital humano. En: Fundación Juan March. Madrid: Boletín informativo N. ${ }^{\circ} 298$.

Rodríguez Giles, E.; Colombo Mac Guire, G.; Delgado, V. (1990). La mujer y la carrera de Ingeniería, Informe final, Universidad Nacional de La Plata, Centro de Estudios de la Mujer.

Rozenblatt, P. (1999). El cuestionamiento del trabajo. Clasificaciones, jerarquía y poder, Buenos Aires, PIETTE CONICET.

Shorter, E. (1977). El nacimiento de la familia moderna. Buenos Aires: Crea.

Suarez, T.; Cánaves, E. (2000). Inserción laboral generizada en la profesión Ingeniería Agronómica. Su vinculación con la vida familiar, Ponencia en 3 . $^{\text {er }}$ Congreso Latinoamericano de Sociología del Trabajo. Buenos Aires.

Testa, J. (1996). Proyecto cambio tecnológico y dinámica de transformación de los perfiles prfesionales en la industria química. En Programa de cooperación técnica entre la secretaria de educación de la ciudad de Buenos Aires y el Ceil Piette Conicet. Buenos Aires: Agencia Nacional de promoción científica y tecnológica Ceil Piette Conicet.

-Palermo, A. I. (1998). La situación ocupacional y profesional de los egresados de la Licenciatura de Ciencias de la Educación de la Universidad Nacional de Luján. Departamento de Educación. Universidad Nacional de Luján.

--------Sanchez, P. (2003). El enfoque de trayectorias educativas y laborales como una mirada complementaria en el tratamiento de la problemática universitaria. Ponencia presentada al Congreso Latinoamericano de Educación Superior en el siglo XXI. San Luis.

Tiramonti, G. y otros. (1993). La nueva oferta universitaria. En Revista del IICE. Año 2, N. ${ }^{\circ}$ 3. Facultad de Filosofía y Letras UBA. Miño y Dávila.

Wainerman, C. (1979). Educación, familia y participación económica femenina en la Argentina, en: "Desarrollo Económico" No 72. Vol. 18. Buenos Aires: IDES.

- (compiladora). (2002). Familia, trabajo y género: Un mundo de nuevas relaciones, UNICEF, Fondo de Cultura Económica, Buenos Aires.

- (2005 a) La vida cotidiana en las nuevas familias ¿una revolución estancada? Buenos Aires: Lumiere.

West, C. y Zimmerman, D. (1999). Haciendo género. En Navarro, Marysa; Stimpson, Caharine: Sexualidad, género y roles sexuales. Fondo de Cultura Económica. Buenos Aires: México.

Williams, C. (1989). Gender differences at work. Women and man in nontraditional occupations. Berkeley: University of California Press. 